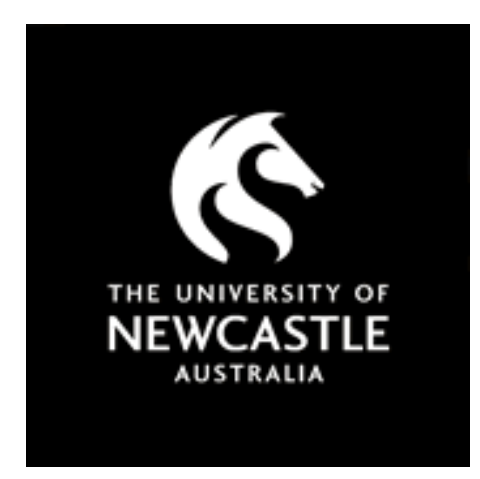

NOVA

University of Newcastle Research Online

nova.newcastle.edu.au

Paul CL, Ishiguchi P, D'Este CA, et al. Testing for type 2 diabetes in Indigenous Australians: guideline recommendations and current practice. Med J Aust 2017; 207 (5): 206-210.

Available from: http://dx.doi.org/10.5694/mja16.00769

(C) Copyright 2017. The Medical Journal of Australia - reproduced with permission.

Accessed from: http://hdl.handle.net/1959.13/1350897 


\section{Testing for type 2 diabetes in Indigenous Australians: guideline recommendations and current practice}

\section{Abstract}

Objectives: To determine the proportion of Aboriginal Controlled Community Health Service (ACCHS) patients tested according to three national diabetes testing guidelines; to investigate whether specific patient characteristics were associated with being tested.

Design, setting and participants: Cross-sectional study of 20978 adult Indigenous Australians not diagnosed with diabetes attending 18 ACCHSs across Australia. De-identified electronic whole service data for July 2010 - June 2013 were analysed.

Main outcomes measures: Proportions of patients appropriately screened for diabetes according to three national guidelines for Indigenous Australians: National Health and Medical Research Council (at least once every 3 years for those aged 35 years or more); Royal Australian College of General Practitioners and Diabetes Australia (at least once every 3 years for those aged 18 years or more); National Aboriginal Community Controlled Health Organisation (annual testing of those aged 18 years or more at high risk of diabetes).

Results: $74 \%(95 \% \mathrm{Cl}, 74-75 \%)$ of Indigenous adults and $77 \%(95 \% \mathrm{Cl}, 76-78 \%)$ of 10760 patients aged 35 or more had been tested for diabetes at least once in the past 3 years. The proportions of patients tested varied between services (range: all adults, 16-90\%; people aged 35 years or more, 23-92\%). 18\% (95\% Cl, 18-19\%) of patients aged 18 or more were tested for diabetes annually (range, $0.1-43 \%$ ). Patients were less likely to be tested if they were under 50 years of age, were transient rather than current patients of the ACCHS, or attended the service less frequently.

Conclusions: Some services achieved high rates of 3-yearly testing of Indigenous Australians for diabetes, but recommended rates of annual testing were rarely attained. ACCHSs may need assistance to achieve desirable levels of testing.

The known Indigenous Australians are at particularly high risk of developing type 2 diabetes, and previous studies have found that the prevalence of undiagnosed diabetes in this population is high.

The new More than three-quarters of adult patients not already diagnosed with diabetes had been tested for diabetes at least once in the past 3 years. Test rates were, however, lower at some services. Most services did not achieve the annual diabetes testing rate recommended by the NACCHO guidelines.

The implications Further investment in improving rates of diabetes testing at a whole service or whole community level could lead to better health outcomes for Indigenous Australians. 
Type 2 diabetes affects a growing proportion of people internationally, ${ }^{1-4}$ incurring substantial social and economic costs. ${ }^{5}$ Diabetes, diagnosed and undiagnosed, is a major independent risk factor for cardiovascular disease, blindness, renal failure and amputation. Some population groups are at particularly high risk of developing diabetes; for example, in the United States, Australia and Canada, its prevalence is much higher in indigenous groups than in the general population..$^{6-8}$ Recent reports indicate that $11.1 \%$ of Aboriginal and Torres Strait Islander (Indigenous Australian) adults have diabetes (with a further $4.7 \%$ at risk of developing it), ${ }^{9}$ more than double the proportion for the overall Australian population (5.1\%). ${ }^{10}$ The largest population-based study of diabetes in Australia found that only half of the estimated $7.4 \%$ of the overall population with diabetes (identified by screening) had previously been diagnosed with the disorder. ${ }^{11} \mathrm{~A}$ smaller study of Indigenous Australians found that its overall prevalence was $17 \%$; one-third of those with diabetes had not yet been diagnosed. ${ }^{12}$ Screening for undetected type 2 diabetes, followed by effective management, is an efficient approach to preventing its complications, an opportunity that is particularly important in populations at high risk. ${ }^{13-15}$

In Australia, Aboriginal Community Controlled Health Services (ACCHSs) serve a predominantly Indigenous client population. ${ }^{16}$ They are therefore an important setting in which to investigate whether these services consistently deliver best practice care to patients at high risk in accordance with guidelines for diabetes testing. The aims of our study were:

- to determine the proportion of ACCHS patients not diagnosed with diabetes who have been tested according to three national diabetes testing guidelines for Indigenous Australian people; and

- to investigate whether person-level characteristics (sex, age, body mass index [BMI], total number of visits, current $v$ transient patient status) were associated with having been tested according to each of the three guidelines.

This cross-sectional study constituted part of the baseline data collection for a larger investigation of diabetes care practices (not yet published).

\section{Methods}

\section{Services}

Each of the approximately 130 ACCHSs operating at the time of the trial (July 2010 - June 2013) were eligible to participate if they employed at least one doctor, and if the Communicare (practice management software) electronic health record and an electronic database for adding patient pathology results to the medical record were used. Eligible services were contacted by mail and telephone, and Aboriginal study investigators undertook face-to-face visits until 18 services (across the seven mainland states and territories) had agreed to participate.

\section{Participants}

De-identified electronic unit record patient data from each participating service were provided by Communicare. Eligible patients were aged 18 years or more, identified as Aboriginal or Torres Strait Islander, and had attended the service during the final 12 months of the study period ( 1 July 2012 30 June 2013). All attendance data for the 3 -year period were obtained in order to compare diabetes testing with each of the three guidelines. 


\section{Measures}

The data provided in the de-identified extract included Indigenous status, type of patient (current or transient patient: assessment by service staff of the patient's relationship with the service), age, date of death, sex, dates of health service visits, weight, height, type 2 diabetes diagnosis status, date of type 2 diabetes diagnosis, blood glucose level laboratory reports (random or fasting), oral glucose tolerance tests (dates and results), glucose point-of-care (finger prick) tests (random or fasting, with dates and results), $\mathrm{HbA}_{1 \mathrm{c}}$ level tests (dates and results).

\section{Definitions of guideline-appropriate testing}

For the purposes of the study, oral glucose tolerance testing, venous glucose level testing (random and fasting), and $\mathrm{HbA}_{1 \mathrm{c}}$ level testing were all deemed appropriate tests for type 2 diabetes. Although $\mathrm{HbA}_{1 \mathrm{c}}$ level testing was not generally recommended for diagnosing type 2 diabetes during the study period, it was employed for this purpose by some services.

The frequency of testing for diabetes during July 2010 - June 2013 was compared with each of three national guidelines:

- National Health and Medical Research Council (NHMRC) of Australia guideline: ${ }^{17}$ Indigenous Australians aged 35 years or more (ie, at the start of the study data collection period) should be tested at least once every 3 years.

- Royal Australian College of General Practitioners and Diabetes Australia (RACGP/DA) guideline: ${ }^{18}$ Indigenous Australians aged 18 years or more (ie, at the start of the study data collection period) should be tested at least once every 3 years.

- National Aboriginal Community Controlled Health Organisation (NACCHO) guideline: ${ }^{19}$ people aged 18 years or more who are at high risk of diabetes as defined in the guideline (ie, at the start of the study data collection period) should be tested annually.

As some patients were diagnosed with diabetes during the study period, adequate testing for each of the guidelines was defined as follows:

- NHMRC and RACGP/DA guidelines: a test was performed or the person was diagnosed with diabetes at any point during the 3-year study period;

- NACCHO guideline: a test was performed in each of the 3 years of the study period, or the person was tested annually until diagnosed with diabetes, after which they were no longer eligible for diabetes testing.

\section{Statistical analysis}

Partially pooled estimates of the proportions of patients tested according to each guideline are reported, predicted by a random intercept logistic regression model with no fixed effects, which adjusts for the correlation of outcomes within services. The association between patient-level characteristics (sex, age, current or transient patient status, number of visits, and BMI) with screening were analysed in multilevel logistic regression models in which patients (level 1 ) were 
nested within services (level 2). Separate models were generated for each guideline, and all models included a random intercept for service; parameters were estimated by maximum likelihood (adaptive Gauss-Hermite approximation). Sensitivity analyses were performed including or excluding patients with missing BMI values; as no overall difference was found between the results of the two approaches, those of the analysis including patients with missing BMI values are reported. Adjusted $P$ values and the odds of being appropriately tested (with $95 \%$ confidence intervals [Cls]) are reported. All statistical analyses were undertaken in SAS 9.4 (SAS Institute).

\section{Ethics approval}

Institutional ethics approvals for this study were provided by the Alfred Hospital Human Research Ethics Committee (reference, 152/11), University of Newcastle Human Research Ethics Committee (reference, $\mathrm{H}-2011-0289$ ), the Aboriginal Health and Medical Research Council Ethics Committee (reference, 952/13), the Western Australian Aboriginal Health Information and Ethics Committee (reference, 331-11/10), the Central Australian Health Research Ethics Committee (reference, HREC12-33), the Royal Darwin Hospital/Menzies School of Health Research Ethics Committee (reference, HOMER-2011-1663) and the Aboriginal Health Council of South Australia Ethics Committee (reference, 04-11-415). As the data were obtained from de-identified electronic health record data, individual patient consent was not required, but patients were informed by signs in the clinics that the service was participating in this study.

\section{Results}

\section{ACCHS patient sample}

Of the 58 eligible services, 31 were approached and 18 (58\%) were recruited for the study. Six services had fewer than 1000 eligible adult patients during the study period; 12 had 1000 or more. The ACCHSs were geographically diverse: three services were in major cities, eight in regional areas, and seven in remote areas. It is not possible to determine whether the participating services were representative of all 130 ACCHSs, as complete service-by-service data are not publicly available. Of the 25924 patients identified by the data extraction process, 20978 (81\%) were Indigenous Australians, and comprised the sample for our study. There were fewer than 500 eligible patients at four services, 500-1000 eligible patients at six services, and more than 1000 eligible patients at eight services (Box 1). 
Box 1 - Characteristics of the study sample of 20978 patients at 18 Aboriginal Community Controlled Health Services

Characteristic Number of patients (\%)

\section{Service-level variables}

Total adult patient volume during the 3-year study period

Services with $<1000$ eligible patients

Services with $\geq 1000$ eligible patients

Remoteness

Major city

Inner regional

Outer regional

Remote

Very remote

\section{Patient-level variables}

Attendance status

Current patient

Transient patient

Sex
Men
Women
9075 (43\%)
11903 (57\%)

Age (years)

$18-34$
$35-50$

$>50$

Number of visits during the 3-year study period

$$
\begin{gathered}
1-4 \\
>4
\end{gathered}
$$

Body mass index $(N=13796)^{*}$

$$
\begin{aligned}
& <25 \mathrm{~kg} / \mathrm{m}^{2} \\
& \geq 25 \mathrm{~kg} / \mathrm{m}^{2}
\end{aligned}
$$

$2163(10 \%)$

$18815(90 \%)$

6695 (32\%)

$1722(8 \%)$

$6001(29 \%)$

$2886(14 \%)$

$3674(18 \%)$

$17741(85 \%)$

$3237(15 \%)$

$10218(49 \%)$

$7441(35 \%)$

$3319(16 \%)$

$4992(24 \%)$

$15986(76 \%)$

$4808(35 \%)$

8988 (65\%)

*The most recent body mass index data were included in the analyses, but the timing of recording varied considerably between patients

\section{The proportions of patients tested for diabetes}

NHMRC guideline: 8330 of 10760 patients aged 35 years or more $(77 \% ; 95 \% \mathrm{Cl}, 76-78 \%)$ had been tested for diabetes as recommended. The proportion varied between services (range, 23-92\%); for 12 of the 18 services, more than $70 \%$ of people aged 35 years or over had been tested at least once during the 3-year period. 
RACGP/DA guideline: 15592 of 20978 patients aged 18 years or more (74\%; $95 \% \mathrm{Cl}, 74-75 \%)$ had been tested for diabetes as recommended. The proportion of patients tested varied between services (range, 16-90\%); for 10 of the 18 services, more than $70 \%$ of people aged 18 years or over had been tested at least once during the 3-year period.

NACCHO guideline: 3826 of 20978 patients aged 18 years or more (18\%; 95\% Cl, 18-19\%) had been tested for diabetes as recommended. The proportion of patients tested varied between services (range, $0.1-43 \%$ ); at 7 of the 18 services, fewer than $10 \%$ of adult patients had been tested annually during the study period (Box 2).

Box 2 - Partially pooled estimates for the proportions of patients tested according to each of the three guidelines

Partially pooled estimate of proportion of patients $(95 \% \mathrm{Cl})$

\begin{tabular}{lccc}
\cline { 2 - 4 } Service & NHMRC & RACGP/DA & NACCHO \\
\hline 1 & $92 \%(84-96 \%)$ & $90 \%(84-94 \%)$ & $43 \%(30-57 \%)$ \\
2 & $85 \%(77-90 \%)$ & $82 \%(74-88 \%)$ & $24 \%(16-35 \%)$ \\
3 & $91 \%(86-95 \%)$ & $88 \%(82-93 \%)$ & $30 \%(20-42 \%)$ \\
4 & $69 \%(56-80 \%)$ & $14 \%(8-24 \%)$ \\
5 & $71 \%(57-82 \%)$ & $68 \%(57-77 \%)$ & $9 \%(6-15 \%)$ \\
6 & $75 \%(65-82 \%)$ & $90 \%(84-93 \%)$ & $21 \%(14-31 \%)$ \\
7 & $90 \%(84-93 \%)$ & $38 \%(24-55 \%)$ & $8 \%(3-18 \%)$ \\
8 & $55 \%(35-74 \%)$ & $88 \%(81-92 \%)$ & $26 \%(17-38 \%)$ \\
9 & $89 \%(83-93 \%)$ & $71 \%(60-80 \%)$ & $9 \%(5-15 \%)$ \\
10 & $72 \%(60-81 \%)$ & $79 \%(70-86 \%)$ & $16 \%(10-25 \%)$ \\
11 & $68 \%(56-78 \%)$ & $16 \%(11-24 \%)$ & $26 \%(17-38 \%)$ \\
12 & $83 \%(75-89 \%)$ & $80 \%(71-87 \%)$ & $0.1 \%(0-1 \%)$ \\
13 & $23 \%(15-33 \%)$ & $78 \%(68-85 \%)$ & $13 \%(8-21 \%)$ \\
14 & $87 \%(80-92 \%)$ & $88 \%(82-92 \%)$ & $17 \%(10-26 \%)$ \\
15 & $81 \%(73-88 \%)$ & $49 \%(37-61 \%)$ & $6 \%(25-49 \%)$ \\
16 & $87 \%(81-92 \%)$ & $55 \%(44-67 \%)$ & $9 \%(5-14 \%)$ \\
17 & $49 \%(37-61 \%)$ & $62 \%(51-73 \%)$ & $8 \%(5-13 \%)$ \\
18 & $64 \%(53-74 \%)$ & $69 \%(58-78 \%)$ &
\end{tabular}

$\mathrm{NACCHO}=$ National Aboriginal Community Controlled Health Organisation; NHMRC $=$ National Health and Medical Research Council; RACGP/DA = Royal Australian College of General Practitioners and Diabetes Australia.

\section{Characteristics associated with having been tested for diabetes}

NHMRC guideline: being younger (aged 35-50 v 50 years or more; $P<0.001$ ), visiting the service four or fewer times ( $v$ more than four times; $P<0.001$ ), and having an unknown or missing BMI ( $v$ having a recorded $\mathrm{BMI}>30 \mathrm{~kg} / \mathrm{m}^{2} ; P<0.001$ ) were all associated with significantly lower odds of appropriate testing. 
RACGP/DA guideline: being younger ( $18-34 v 70$ years or more; $P<0.001)$, visiting the service four or fewer times ( $v$ more than four times; $P<0.001$ ); and having an unknown or missing BMI or a BMI below $25 \mathrm{~kg} / \mathrm{m}^{2}$ ( $v$ a recorded BMI of $30 \mathrm{~kg} / \mathrm{m}^{2}$ or more; $P<0.001$ and $P=0.031$ respectively) were all associated with significantly lower odds of appropriate testing.

NACCHO guideline: being male $(P<0.001)$, younger $(18-34$ years $v 70$ or more; $P<0.001)$, visiting the service four or fewer times ( $v$ more than four times; $P<0.001$ ), and having a missing or unknown $\mathrm{BMI}$ or $\mathrm{BMI}$ below $30 \mathrm{~kg} / \mathrm{m}^{2}$ ( $v$ a recorded $\mathrm{BMI}$ of $30 \mathrm{~kg} / \mathrm{m}^{2}$ or more; $P<0.001$ ) were all associated with significantly lower odds of appropriate testing. Being a current rather than transient patient $(P$ $<0.001$ ) was associated with higher odds of being tested for diabetes in accordance with the NACCHO guideline (Box 3 ).

Box 3 - The influence of patient- and service-related characteristics on the odds of appropriate testing according to the three diabetes testing guidelines (adjusted models)

\begin{tabular}{|c|c|c|c|c|c|c|c|c|c|}
\hline \multirow[b]{2}{*}{ Characteristic } & \multicolumn{3}{|c|}{ NHMRC } & \multicolumn{3}{|c|}{ RACGP/DA } & \multicolumn{3}{|c|}{ NACCHO } \\
\hline & Tested* & $\begin{array}{c}\text { aOR } \\
(95 \% \mathrm{Cl})\end{array}$ & $P$ & Tested* & $\begin{array}{c}\text { aOR } \\
(95 \% \mathrm{Cl})\end{array}$ & $P$ & Tested* & $\begin{array}{c}\text { aOR } \\
(95 \% \mathrm{Cl}) \\
\end{array}$ & $P$ \\
\hline Number of patients & 8330 & & & 15592 & & & 3826 & & \\
\hline Remoteness & & & 1.0 & & & 0.94 & & & 0.92 \\
\hline Major city & $\begin{array}{l}2789 \\
(79 \%)\end{array}$ & $\begin{array}{c}0.93 \\
(0.20- \\
4.35)\end{array}$ & & $\begin{array}{l}4983 \\
(74 \%)\end{array}$ & $\begin{array}{c}0.89 \\
(0.19- \\
4.15)\end{array}$ & & $\begin{array}{c}995 \\
(15 \%)\end{array}$ & $\begin{array}{c}0.75 \\
(0.14- \\
4.10)\end{array}$ & \\
\hline $\begin{array}{l}\text { Inner/outer } \\
\text { regional }\end{array}$ & $\begin{array}{l}3273 \\
(80 \%)\end{array}$ & $\begin{array}{c}1.00 \\
(0.33- \\
3.05)\end{array}$ & & $\begin{array}{l}5800 \\
(75 \%)\end{array}$ & $\begin{array}{c}0.83 \\
(0.27- \\
2.49)\end{array}$ & & $\begin{array}{l}1274 \\
(16 \%)\end{array}$ & $\begin{array}{c}0.81 \\
(0.24- \\
2.74)\end{array}$ & \\
\hline $\begin{array}{l}\text { Remote/very } \\
\text { remote }\end{array}$ & $\begin{array}{l}2268 \\
(72 \%)\end{array}$ & 1 & & $\begin{array}{l}4809 \\
(73 \%)\end{array}$ & 1 & & $\begin{array}{l}1557 \\
(24 \%)\end{array}$ & 1 & \\
\hline $\begin{array}{l}\text { Adult patient } \\
\text { volume }\end{array}$ & & & 0.36 & & & 0.48 & & & 0.89 \\
\hline$<1000$ & $\begin{array}{c}662 \\
(65 \%)\end{array}$ & $\begin{array}{c}0.58 \\
(0.19- \\
1.83)\end{array}$ & & $\begin{array}{l}1419 \\
(66 \%)\end{array}$ & $\begin{array}{c}0.66 \\
(0.22- \\
2.05)\end{array}$ & & $\begin{array}{c}317 \\
(15 \%)\end{array}$ & $\begin{array}{c}1.10 \\
(0.32- \\
3.80)\end{array}$ & \\
\hline$\geq 1000$ & $\begin{array}{l}7668 \\
(79 \%)\end{array}$ & 1 & & $\begin{array}{c}14173 \\
(75 \%)\end{array}$ & 1 & & $\begin{array}{l}3509 \\
(19 \%)\end{array}$ & 1 & \\
\hline $\begin{array}{l}\text { Patient-clinic } \\
\text { relationship }\end{array}$ & & 0.70 & & & 0.54 & & & $<0.001$ & \\
\hline Current patient & $\begin{array}{l}7166 \\
(80 \%)\end{array}$ & $\begin{array}{c}0.97 \\
(0.81- \\
1.15)\end{array}$ & & $\begin{array}{c}13463 \\
(76 \%)\end{array}$ & $\begin{array}{c}1.04 \\
(0.92- \\
1.17)\end{array}$ & & $\begin{array}{l}3576 \\
(20 \%)\end{array}$ & $\begin{array}{c}2.85 \\
(2.43- \\
3.33)\end{array}$ & \\
\hline Transient patient & $\begin{array}{l}1164 \\
(66 \%)\end{array}$ & 1 & & $\begin{array}{l}2129 \\
(66 \%)\end{array}$ & 1 & & $\begin{array}{c}250 \\
(7.7 \%)\end{array}$ & 1 & \\
\hline Sex & & & 0.94 & & & 0.14 & & & $<0.001$ \\
\hline
\end{tabular}




\begin{tabular}{|c|c|c|c|c|c|c|c|c|c|}
\hline Men & $\begin{array}{l}3747 \\
(77 \%)\end{array}$ & $\begin{array}{c}1.00 \\
(0.88- \\
1.12)\end{array}$ & & $\begin{array}{c}6606 \\
(73 \%)\end{array}$ & $\begin{array}{c}0.94 \\
(0.86- \\
1.02)\end{array}$ & & $\begin{array}{c}1473 \\
(16 \%)\end{array}$ & $\begin{array}{c}0.80 \\
(0.73- \\
0.87)\end{array}$ & \\
\hline Women & $\begin{array}{l}4583 \\
(77 \%)\end{array}$ & 1 & & $\begin{array}{l}8986 \\
(75 \%)\end{array}$ & 1 & & $\begin{array}{c}2353 \\
(20 \%)\end{array}$ & 1 & \\
\hline Age (years) & & & $<0.001$ & & & $<0.001$ & & & $<0.001$ \\
\hline $18-34$ & NA & - & & $\begin{array}{c}7262 \\
(71 \%)\end{array}$ & $\begin{array}{c}0.49 \\
(0.34- \\
0.70)\end{array}$ & & $\begin{array}{c}1423 \\
(14 \%)\end{array}$ & $\begin{array}{c}0.19 \\
(0.14- \\
0.27)\end{array}$ & \\
\hline $35-50$ & $\begin{array}{l}5722 \\
(77 \%)\end{array}$ & $\begin{array}{c}0.78 \\
(0.68- \\
0.89)\end{array}$ & & $\begin{array}{c}5722 \\
(77 \%)\end{array}$ & $\begin{array}{c}0.80 \\
(0.55- \\
1.14)\end{array}$ & & $\begin{array}{c}1499 \\
(20 \%)\end{array}$ & $\begin{array}{c}0.36 \\
(0.26- \\
0.51)\end{array}$ & \\
\hline$\geq 50$ & $\begin{array}{c}2608 \\
(79 \%)\end{array}$ & 1 & & NA & - & & NA & - & \\
\hline $51-70$ & NA & - & & $\begin{array}{c}2402 \\
(79 \%)\end{array}$ & $\begin{array}{c}1.03 \\
(0.71- \\
1.49)\end{array}$ & & $\begin{array}{c}816 \\
(27 \%)\end{array}$ & $\begin{array}{c}0.62 \\
(0.44- \\
0.86)\end{array}$ & \\
\hline$\geq 70$ & NA & - & & $\begin{array}{c}206 \\
(75 \%)\end{array}$ & 1 & & $\begin{array}{c}88 \\
(32 \%)\end{array}$ & 1 & \\
\hline Number of visits & & & $<0.001$ & & & & & & $<0.001$ \\
\hline$<4$ & $\begin{array}{l}1173 \\
(49 \%)\end{array}$ & $\begin{array}{c}0.23 \\
(0.20- \\
0.27)\end{array}$ & & $\begin{array}{c}2371 \\
(47 \%)\end{array}$ & $\begin{array}{c}0.26 \\
(0.24- \\
0.29)\end{array}$ & $<0.001$ & $\begin{array}{c}25 \\
(0.5 \%)\end{array}$ & $\begin{array}{c}0.03 \\
(0.02- \\
0.05)\end{array}$ & \\
\hline$>4$ & $\begin{array}{l}7157 \\
(86 \%)\end{array}$ & 1 & & $\begin{array}{c}13221 \\
(83 \%)\end{array}$ & 1 & - & $\begin{array}{c}3801 \\
(24 \%)\end{array}$ & 1 & \\
\hline Body mass index & & & $<0.001$ & & & $<0.001$ & & & $<0.001$ \\
\hline Missing/unknown & $\begin{array}{l}1665 \\
(45 \%)\end{array}$ & $\begin{array}{c}0.07 \\
(0.06- \\
0.08)\end{array}$ & & $\begin{array}{c}2928 \\
(41 \%)\end{array}$ & $\begin{array}{c}0.07 \\
(0.07- \\
0.08)\end{array}$ & & $\begin{array}{c}151 \\
(2.1 \%)\end{array}$ & $\begin{array}{c}0.07 \\
(0.06- \\
0.09)\end{array}$ & \\
\hline$<25 \mathrm{~kg} / \mathrm{m}^{2}$ & $\begin{array}{l}2106 \\
(94 \%)\end{array}$ & $\begin{array}{c}1.01 \\
(0.78- \\
1.30)\end{array}$ & & $\begin{array}{c}4396 \\
(91 \%)\end{array}$ & $\begin{array}{c}0.84 \\
(0.72- \\
0.98)\end{array}$ & & $\begin{array}{c}1118 \\
(23 \%)\end{array}$ & $\begin{array}{c}0.57 \\
(0.52- \\
0.63)\end{array}$ & \\
\hline $25-29.9 \mathrm{~kg} / \mathrm{m}^{2}$ & $\begin{array}{l}1890 \\
(94 \%)\end{array}$ & $\begin{array}{c}1.02 \\
(0.79- \\
1.33)\end{array}$ & & $\begin{array}{c}3464 \\
(92 \%)\end{array}$ & $\begin{array}{c}0.94 \\
(0.80- \\
1.11)\end{array}$ & & $\begin{array}{c}1003 \\
(27 \%)\end{array}$ & $\begin{array}{c}0.80 \\
(0.72- \\
0.88)\end{array}$ & \\
\hline$\geq 30 \mathrm{~kg} / \mathrm{m}^{2}$ & $\begin{array}{c}2669 \\
(94 \%)\end{array}$ & 1 & & $\begin{array}{c}4804 \\
(92 \%)\end{array}$ & 1 & & $\begin{array}{c}1554 \\
(30 \%)\end{array}$ & 1 & \\
\hline
\end{tabular}

$\mathrm{aOR}=$ adjusted odds ratio; $\mathrm{NA}=$ not applicable; $\mathrm{NACCHO}=$ National Aboriginal Community Controlled Health Organisation; NHMRC = National Health and Medical Research Council; RACGP/DA = Royal Australian College of General Practitioners and Diabetes Australia. * Number (proportion) of patients tested according to guideline.

Results from unadjusted and adjusted models that included or excluded BMI for each of the three guidelines are included in the online Appendix. 


\section{Discussion}

While preventing diabetes is the primary goal of any health service, early diagnosis is also essential for averting and reducing complications. The NACCHO guideline promotes annual testing for Indigenous Australians at high risk of diabetes, and general practitioners can request annual Indigenous-specific health assessments under item 715 of the Medicare Benefits Schedule (MBS). Annual diabetes testing might therefore be considered appropriate by the investigated services and providers. However, we found that the rates of annual testing were low (mean, 18\%; range, 0.144\%), comparable with the overall uptake of Indigenous-specific health checks during 2014-15 (23.8\%). ${ }^{20}$ Our study did not investigate the reasons for low rates of annual testing, nor whether they were influenced by providers not being aware of guideline recommendations, clinical judgements about the appropriateness of the guideline, funding-related implementation problems, or practical impediments, such as infrequent patient attendance. Further, each ACCHS is an independently managed community-based primary health organisation, and is therefore not obliged to implement specific guidelines. In contrast, good rates of 3-yearly testing were achieved in our study by most ACCHSs - few services had rates below $50 \%$, and most had rates above $70 \%$ - indicating the acceptability of 3-yearly testing.

The finding that younger people (18-50-year-olds) were less likely to undergo annual or 3-yearly testing than older Indigenous Australians is intuitively reasonable, as the risk of developing diabetes rises with age ${ }^{21}$ increasing the need for testing. However, it is important that health services also consider the benefits of focusing greater effort on regularly testing younger patients. Indigenous Australians aged 25-34 years are five times more likely to have diabetes or high blood sugar levels than non-Indigenous Australians of the same age $(5.1 \% v 0.9 \%) .{ }^{21} \mathrm{~A}$ substantial opportunity for limiting the impact of type 2 diabetes, by ensuring that younger people at high risk undergo regular testing and receive care if needed, ${ }^{22}$ is being missed. If best practice guidelines were restricted to those aged 35 or more, a substantial proportion of people at high risk would be not be tested. Finally, having a known BMI was associated in our study with higher odds of appropriate testing; assessing and recording of $\mathrm{BMI}$ in health practice should therefore be encouraged.

A major strength of our study was our analysing whole service data from a geographically diverse group of ACCHSs. Community members who rarely attend their ACCHS are likely to be underrepresented in these data, and patients who moved during the study period or attended a non-study ACCHS may have had tests not recorded in the study dataset. However, the true population-level proportion of patients who were tested appropriately may be lower than we have reported, as patients who did not attend during the final 12-month period of the study were excluded from the analysis. It should be noted that we could not assess the full range of potentially relevant patient factors that may be important for Indigenous Australians. Community-level factors could not be taken into account, nor were clinical factors examined, such as comorbidities that may influence clinicians' judgements about the relative importance of diabetes testing for an individual patient. Further, guideline adherence was not analysed according to the type of test requested. Finally, other guidelines may include recommendations not explored by our study.

\section{Conclusions}

Given the relative success of most ACCHSs in meeting 3-yearly targets for testing adult Indigenous Australians for diabetes and the importance of testing populations at particular risk from a younger age, the RACGP/DA guideline is probably the most practicable for ACCHSs. Particular attention should be given to screening patients who do not attend ACCHSs regularly, transient patients, and 
those under 50 years of age. Further investment in improving performance at a whole service or whole community level in some locations is also needed.

\section{References}

1. Australian Institute of Health and Welfare. Diabetes and disability: impairments, activity limitations, participation restrictions and comorbidities (AIHW Cat. No. CVD 63; Diabetes Series No. 20). Canberra: AlHW, 2013.

2. Public Health Agency of Canada. Diabetes in Canada: facts and figures from a public health perspective. Ottawa: Chronic Disease Surveillance and Monitoring Division, 2011. http://www.phacaspc.gc.ca/cd-mc/publications/diabetes-diabete/facts-figures-faits-chiffres-2011/index-eng.php (accessed June 2017).

3. Centers for Disease Control and Prevention. 2014 National diabetes statistics report. Atlanta: US Department of Health and Human Services, 2014. https://www.cdc.gov/diabetes/data/statistics/2014statisticsreport.html (accessed June 2017).

4. Holman N, Young B, Gadsby R. Current prevalence of type 1 and type 2 diabetes in adults and children in the UK. Diabet Med 2015; 32: 1190-1120.

5. Zimmet P, Alberti K, Shaw J. Global and societal implications of the diabetes epidemic. Nature 2001; 414: 782-787.

6. Young TK, Reading J, Elias B. Type 2 diabetes mellitus in Canada's First Nations: status of an epidemic in progress. CMAJ 2000; 163: 561-566.

7. Acton KJ, Ríos Burrows N, Moore K, et al. Trends in diabetes prevalence among American Indian and Alaska native children, adolescents, and young adults. Am J Public Health 2002; 92: 1485-1490.

8. Australian Institute of Health and Welfare. National key performance indicators for Aboriginal and Torres Strait Islander primary health care: results from December 2013 (AlHW Cat. No. IHW 146). Canberra: AlHW, 2014.

9. Australian Bureau of Statistics. 4727.0.55.003. Australian Aboriginal and Torres Strait Islander health survey: biomedical results, 2012-13. Sept 2014.

http://www.abs.gov.au/AUSSTATS/abs@.nsf/DetailsPage/4727.0.55.0032012-13?OpenDocument (accessed June 2017).

10. Australian Bureau of Statistics. 4364.0.55.001. National Health Survey: first results, 2014-15. Dec 2015. http://www.abs.gov.au/ausstats/abs@.nsf/mf/4364.0.55.001 (accessed June 2017).

11. Dunstan DW, Zimmet PZ, Welborn TA, et al. The rising prevalence of diabetes and impaired glucose tolerance: the Australian Diabetes, Obesity and Lifestyle study. Diabetes Care 2002; 25: 829834.

12. O'Dea K, Cunningham J, Maple-Brown L, et al. Diabetes and cardiovascular risk factors in urban Indigenous adults: results from the DRUID study. Diabetes Res Clin Pract 2008; 80: 483-489.

13. Engelgau MM, Narayan K, Herman WH. Screening for type 2 diabetes. Diabetes Care 2000; 23: 1563-1580.

14. Waugh $N$, Scotland $G$, McNamee $P$, et al. Screening for type 2 diabetes: literature review and economic modelling. Health Technol Assess 2007; 11: iii-iv, ix-xi, 1-125. 
15. Colagiuri S, Davies D, Girgis S, Colagiuri R. National evidence based guideline for case detection and diagnosis of type 2 diabetes. Canberra: Diabetes Australia, NHMRC, 2009.

https://www.nhmrc.gov.au/ files nhmrc/file/publications/synopses/di17-diabetes-detectiondiagnosis.pdf (accessed July 2017).

16. Bell K, Couzos S, Daniels J, et al. Aboriginal community controlled health services. In: Department of Health and Aged Care. General practice in Australia, 2000. Canberra: General Practice Branch, Health Services Division, Department of Health and Aged Care, 2000; pp. 74-103.

17. Diabetes Australia Guideline Development Consortium. National evidence based guidelines for the management of type 2 diabetes mellitus. Canberra: NHMRC, 2004.

https://www.nhmrc.gov.au/guidelines-publications/di7-di8-di9-di10-di11-di12-di13 (accessed June 2017).

18. Royal Australian College of General Practitioners, Diabetes Australia. General practice management of type 2 diabetes - 2014-15. Melbourne: RACGP/DA, 2014.

https://www.clinicalguidelines.gov.au/portal/2390/general-practice-management-type-2-diabetes2014-15 (accessed June 2017).

19. Coleman J. Type 2 diabetes prevention and early detection. In: NACCHO/RACGP. National guide to a preventive health assessment for Aboriginal and Torres Strait Islander people. 2nd edition.

Melbourne: RACGP, 2012; pp. 229-238. http://www.racgp.org.au/your-practice/guidelines/nationalguide/type-2-diabetes-prevention-and-early-detection/ (accessed June 2017).

20. Australian Institute of Health and Welfare. Indigenous health check (MBS 715) data tool. http://www.aihw.gov.au/indigenous-australians/indigenous-health-check-data-tool/ (accessed Dec 2016).

21. Australian Bureau of Statistics. 4727.0.55.001. Australian Aboriginal and Torres Strait islander health survey: first results, Australia (2012-2013). Nov 2013.

http://www.abs.gov.au/ausstats/abs@.nsf/mf/4727.0.55.001 (accessed July 2015).

22. Bloomgarden ZT. Type 2 diabetes in the young: the evolving epidemic. Diabetes Care 2004; 27: 998-1010. 